\title{
EL PRINCIPIO DE PROPORCIONALIDAD COMO CANON DE CONSTITUCIONALIDAD: UNA APROXIMACIÓN AL CASO ECUATORIANO
}

\author{
Sebastián López Hidalgo \\ doi: http://dx.doi.org/10.18543/ed-65(1)-2017pp185-217
}

\begin{abstract}
SUMARIO: 1. PRECISIÓN CONCEPTUAL DEL PRINCIPIO DE PROPORCIONALIDAD. 2. ESTRUCTURA DEL PRINCIPIO DE PROPORCIONALIDAD. 3. El PRINCIPIO DE PROPORCIONALIDAD COMO CANON DE CONSTITUCIONALIDAD: EL Caso ecuatoriano. 3.1. Corte Constitucional de Transición. 3.2. Primera Corte Constitucional. 4. REFLEXIONES FINALES.
\end{abstract}

\section{PRECISIÓN CONCEPTUAL DEL PRINCIPIO DE PROPORCIONALIDAD}

El principio de proporcionalidad es un concepto e instrumento jurídico que aparece cada vez con mayor frecuencia en la motivación de las decisiones de las cortes o tribunales contemporáneos como canon para controlar la actividad legislativa que riñe con el contenido de los derechos fundamentales.

Ahora, como lo ha puesto de manifiesto Bernal Pulido, no se trata de un concepto jurídico inventado por la jurisprudencia y la doctrina constitucional de la segunda mitad del siglo Xx. La relación medio-fin que subyace a una idea de proporcionalidad se reveló como una forma de pensamiento en la 
filosofía práctica de la Grecia clásica ${ }^{1}$. Sin embargo, el resurgimiento del principio como concepto del Derecho europeo se remonta al contractualismo iusnaturalista de la Ilustración, cuando maduraron los demás presupuestos del Derecho moderno, fundamentalmente del Derecho penal ${ }^{2}$.

La nueva concepción liberal del Estado y de la actividad de policía que surge en el siglo XIX, caracterizada por el reforzamiento de la protección de las esferas jurídicas individuales mediante el reconocimiento de una serie de derechos que limitan la intervención del Estado en el ejercicio de su potestad de policía, determina un claro desarrollo del principio de proporcionalidad en la práctica jurídica ${ }^{3}$.

En principio, todo el discurso de los derechos públicos subjetivos alimentó la concepción individualista frente al Estado, restringiendo toda actividad de intervención estatal a circunstancias excepcionales, y siempre que fuese necesaria y proporcional ${ }^{4}$, con lo cual, el principio de proporcionalidad comenzaría a aplicarse en las más variadas áreas del Derecho administrativo, especialmente el administrativo sancionador y, con primordial relevancia en el ámbito del Derecho penal ${ }^{5}$, con el fin de evitar un exceso de intervención sobre el contenido de los derechos.

Tras la consolidación del Estado democrático, la utilización del principio de proporcionalidad se ha generalizado y ha venido a desempeñar un papel

${ }^{1}$ Sobre la génesis y los antecedentes del principio de proporcionalidad en el derecho público europeo $\mathrm{y}$, concretamente, en el caso español, se pude consultar Carlos BERNAL PULIDO, El principio de proporcionalidad y los derechos fundamentales, (Madrid: Centro de Estudios Políticos y Constitucionales, 2005), 39 y ss. También puede consultarse Javier BARNÉS, «El principio de proporcionalidad. Estudio preliminar» en Cuadernos de Derecho Público, n. ${ }^{\circ}$ 5, (1998): 23 y ss.

2 Luigi FerRajoli, Derecho y razón. Teoría del garantismo penal, (Madrid: Trotta, 1995), 398.

3 Isabel Perello DomenECH, «El principio de proporcionalidad y la jurisprudencia constitucional», en Jueces para la Democracia, n. ${ }^{\circ}$ 28, (1997): 69.

${ }^{4}$ George JellineK, Teoría General del Estado, (Granada: Comares, 2000), 205.

${ }_{5}^{5}$ Entre otros, pueden verse Teresa AGUADo CORREA, El principio de proporcionalidad en derecho penal, (Madrid: EDERSA, 1999); Nicolás GONZÁLEZ - CuELLAR, Principio de proporcionalidad y derechos fundamentales en el proceso penal, (Madrid: Colex, 1990); José Luis DíEZ RIPOLLÉs, «El control de constitucionalidad de las leyes penales» en Revista Española de Derecho Constitucional, n. ${ }^{\circ}$ 75, (2005): 59-106; Gloria LOPERA Mesa, Principio de proporcionalidad y ley penal, (Madrid: Centro de Estudios Políticos y Constitucionales, 2006); Santiago MIR PUIG, «Principio de proporcionalidad y fines del derecho penal» en Estudios en memoria de José María Lidón, ed. Por Juan Echano BASALdÚA (Bilbao: Universidad de Deusto, 2002), 349-366; Hernán Fuentes CuBILlo, «El principio de proporcionalidad en el Derecho Penal. Algunas consideraciones acerca de su concretización en el ámbito de la individualización de la pena» en Revista Ius Et Praxis, n. ${ }^{\circ}$, (2014): 15-42. 
relevante no solamente en el área del Derecho penal o del Derecho administrativo $^{6}$, sino, fundamentalmente, en el área del Derecho constitucional y de los Derechos humanos, ocupando un rol importante en la fundamentación de las decisiones tanto de los tribunales internos, como de los tribunales internacionales de derechos humanos ${ }^{7}$.

La generalizada aceptación que hoy en día goza en la doctrina jurídica el principio de proporcionalidad conlleva que todos los poderes públicos estén sometidos al mismo en una doble vertiente, es decir, como criterio de actuación y como parámetro de control. De manera que «todos los poderes públicos, sea cual sea su ámbito y modo de actuación, deben actuar, pues, de conformidad con el principio de proporcionalidad y, a su vez, pueden ser controlados jurisdiccionalmente desde esta perspectiva» ${ }^{8}$.

No obstante, es evidente que la diversa posición institucional del legislador, de los órganos administrativos y de los tribunales, supone que su vinculación al principio de proporcionalidad difiera tanto en el plano del control como en el de la actuación de cada uno de estos órganos 9 .

En el ámbito del control de constitucionalidad, ha sido la jurisprudencia del Tribunal Constitucional alemán la precursora en la aplicación de éste principio respecto de los actos provenientes de los poderes públicos en materia de derechos fundamentales ${ }^{10}$, línea que ha sido seguida y emulada posteriormente por diferentes Cortes o Tribunales, entre ellas, la Corte Constitucional ecuatoriana.

${ }^{6}$ Teresa Aguado Correa, El principio de proporcionalidad en el Derecho Penal, (Madrid: EDERSA, 1999), 79 y ss.

7 Bardo FASSBENDER, «El principio de proporcionalidad en la jurisprudencia del Tribunal Europeo de Derecho Humanos», en Cuadernos de Derecho Público, n. ${ }^{\circ}$ 5, (1998): 52 y ss.; Javier BARNÉs, «El principio de proporcionalidad. Estudio preliminar» en Cuadernos de Derecho Público, n. ${ }^{\circ} 5$ (1998): 15-49.

${ }^{8}$ Markus GonZÁlez BeILfus, El principio de proporcionalidad en la jurisprudencia del Tribunal Constitucional, 2da. ed. (Navarra: Aranzadi-Thomson S.A., 2015), 79.

9 Ibíd.

${ }^{10}$ En Alemania, la sentencia dictada en el famoso caso de las farmacias inauguraría una tendencia en la que el principio de proporcionalidad constituye la piedra angular de la fundamentación de las decisiones de control constitucional sobre los actos que intervienen en los derechos fundamentales. De acuerdo con dicha línea jurisprudencial, toda intervención estatal en los derechos fundamentales que no cumpla las exigencias de los subprincipios de la proporcionalidad debe ser declarada inconstitucional. Véase, Carlos Bernal Pulido, El principio de proporcionalidad y los derechos fundamentales, (Madrid: Centro de Estudios Políticos y Constitucionales, 2005), 5051, nota al pie 40. No obstante, Enrique Alonso sugiere que los orígenes de este test se encuentran en la jurisprudencia norteamericana. Véase, Enrique Alonso GARCíA, La interpretación de la Constitución, (Madrid: Centro de Estudios Constitucionales, 1984), 204 y ss. 
Sin embargo, una de las deficiencias más notorias que puede evidenciarse en relación con el principio de proporcionalidad es aquella que se refiere a su inconsistencia terminológica ${ }^{11}$. Este problema se presenta con particular evidencia en el uso intercambiable y confuso que se genera entre los términos proporcionalidad y ponderación.

Con mucha probabilidad una de las causas de este problema estriba en la pluralidad de significados o el uso disímil que puede adscribirse al término ponderación ${ }^{12}$. Pero, también, es probable según Arroyo Jiménez «que esta oscuridad esté asociada al hecho de que, aunque en algunas jurisdicciones hayan adquirido una cierta estabilidad, ambas técnicas se encuentran en permanente evolución, tanto por lo que atañe a su contenido y funciones, como por lo que se refiere a su ámbito de aplicación» ${ }^{13}$.

Así, por ponderación se puede entender «una forma de argumentación plausible cuando nos hallamos en presencia de razones justificatorias del mismo valor y tendencialmente contradictorias, algo que suele ocurrir con frecuencia en el ámbito de los derechos fundamentales» ${ }^{14}$. En otros términos, una forma de «sopesar razones que juega a favor y en contra de una específica solución, un método jurídico contrapuesto a la subsunción....» ${ }^{15}$.

${ }^{11}$ Sobre la caracterización del principio de proporcionalidad y su diferenciación con otros principios interpretativos como interdicción de la arbitrariedad, razonabilidad, concordancia práctica e igualdad, puede consultarse Markus GonzÁLEz BEILfus, El principio de proporcionalidad en la jurisprudencia del Tribunal Constitucional..., 82 y ss.

${ }_{12}$ Carlos Bernal Pulido, El principio de proporcionalidad y los derechos fundamentales, (Madrid: Centro de Estudios Políticos y Constitucionales, 2005), 565.

${ }^{13}$ Luis ARROYo JIMÉNEZ, «Ponderación, proporcionalidad y derecho administrativo» en Ponderación y Derecho Administrativo, ed. Por Luis ORTEGa y Susana DE LA SIERRA (coords.), (Barcelona: Marcial Pons, 2009), 33.

${ }^{14}$ Luis Prieto Sanchís, «El constitucionalismo de los derechos» en Miguel Carbonell, Teoría del neoconstitucionalismo (Madrid: Trotta, 2007), 220.

15 Bernal Pulido, El principio de proporcionalidad y los derechos fundamentales..., 565 . 
El juicio de ponderación supone un método argumenta $1{ }^{16}$ que se exterioriza y controla desde sus propias reglas (ley de la ponderación) ${ }^{17}$, con el fin de dar una prevalencia a una de las razones en conflicto ${ }^{18}$.

${ }^{16}$ Para Zagrebelsky, los métodos hacen referencia a los medios o instrumentos a través de los cuales se vuelve efectiva una actividad interpretativa en concreto. Véase Gustavo ZaGreBelsKy, El derecho dúctil, (Madrid: Trotta, 1992), 134.

17 Robert AlEXY, Teoría de los derechos fundamentales, (Madrid: Centro de Estudios Constitucionales, 1993), 160 y ss. Sobre la ley de la ponderación también puede consultarse el artículo de Robert ALEXY, «La fórmula del peso» en Miguel CARBOnELL, El principio de proporcionalidad y la interpretación constitucional, (Quito: Ministerio de Justicia y Derechos Humanos, 2008), 13-42. Como referiría José Juan Moreso: «Según Alexy, la ponderación puede ser dividida en tres etapas. La primera comporta el establecimiento del grado de no satisfacción del primer principio. La segunda etapa consiste en establecer el grado de satisfacción del principio en pugna con el primero. Finalmente, la tercera etapa evalúa si la importancia de la satisfacción del segundo principio justifica la falta de satisfacción del primero. Podemos dividir el grado de afección a un derecho determinado en tres rangos: leve, medio y grave. Como es obvio, estos grados de afección son relativos al contexto establecido por el caso concreto. De ello resulta lo siguiente: las vulneraciones leves de un derecho fundamental ceden ante la protección media y la grave de otro derecho fundamental, y las medias ceden ante las graves. Quedan tres casos de empate, en donde -si entiendo bien la propuesta de Alexy- el legislador goza de discreción para afectar uno u otro derecho, lo que equivale a decir que, en los casos de empate, las restricciones legislativas al ejercicio de un derecho fundamental están justificadas.» Véase, José Juan MorESO, «Alexy y la aritmética de la ponderación» en El principio de proporcionalidad y la interpretación constitucional, ed. Por Miguel CARBONELL (Quito: Ministerio de Justicia y Derechos Humanos, 2008), 71-72.

18 Sobre la ponderación y sus críticas Jürgen Habermas ha indicado que: «...la ponderación o sopesamiento de valores se efectúa, o bien de forma discrecional o arbitraria, o bien de forma no reflexiva, es decir, conforme a estándares o a jerarquías a los que se está acostumbrado. En la medida en que un tribunal constitucional adopta la -teoría de los valores- o -teoría del orden valorativa - y la pone a la base de su práctica de toma de decisiones, aumenta el peligro de juicio irracionales porque con ello cobran primacía los argumentos funcionalistas a costa de los argumentos normativos...En cambio, en cuanto los derechos fundamentales son tomados en serio en su sentido deontológico, quedan sustraídos a tal análisis -costes-beneficios-.Véase, Jürgen HABERMAS, Facticidad y validez, (Madrid: Trotta, 1998), 332. Una respuesta a la posición de Habermas, adoptada por Alexy puede consultarse en Robert ALEXY, «Derechos fundamentales, ponderación y racionalidad» en, El canon neoconstitucional, ed. Por Miguel CARBonell y Leonardo GARCÍA (Madrid: Trotta, 2010), 106-116. Igualmente puede consultarse sobre la crítica: Antonio GARCía AMADO, «Derechos y pretextos» en Teoría del Neoconstitucionalismo, ed. Por Miguel Carbonell, (Madrid: Trotta, 2007). Finalmente, un análisis interesante de la crítica y defensa a la ponderación como método, puesto que resume un debate más amplio respecto del modelo neoconstitucionalista mantenido entre García Amado y Prieto Sanchís, puede verse en: Carlos BERNAL PULIDO, El Neoconstitucionalismo y la normatividad del derecho. Escritos de derecho constitucional y filosofia del derecho, (Colombia: Universidad Externado, Bogotá, 2009). 
Dicho en otras palabras, se trataría de un instrumento que explicita las circunstancias específicas en la cuales un derecho prima sobre otro en un caso concreto, en una suerte de jerarquía móvil o axiológica ${ }^{19}$, lo que significa, según la regla constitutiva de la ley de la ponderación, que, «cuanto mayor es el grado de la no satisfacción o de afectación de un principio, tanto mayor tiene que ser la importancia de la satisfacción del otro» ${ }^{20}$.

Dentro del campo específico de los derechos fundamentales el tema no es pacífico y puede afirmarse que, mientras algunos autores opinan que ponderación y proporcionalidad son nociones sinónimas ${ }^{21}$, otros indican que se trata de ideas contrapuestas, bajo el entendido de que la ponderación es un método de decisión, mientras que el juicio de proporcionalidad es un método de control en relación con el grado de restricción de los derechos, aun cuando ambos conceptos puedan estar relacionados ${ }^{22}$. Hay finalmente quienes consideran que su coincidencia es solo parcial ${ }^{23}$.

19 Luis Prieto SANChís, «El constitucionalismo de los derechos» en Teoría del neoconstitucionalismo, ed. Por Miguel CARBonell (Madrid, Trotta, 2007), 220.

${ }^{20}$ Robert Alexy, Teoría de los derechos fundamentales..., 161. Una regla de la ponderación que coincide con la definición que trae la Ley Orgánica de Garantías Jurisdiccionales y Control Constitucional del Ecuador en su art. 3, numeral 3 cuando manifiesta: «...Cuanto mayor sea el grado de la no satisfacción o de afectación de un derecho o principio, tanto mayor tiene que ser la importancia de la satisfacción del otro».

${ }^{21}$ Francisco Velasco CABAllero, «Método de la ponderación y sistema competencial» en, Ponderación y Derecho Administrativo, ed. Por Luis ORTEGa y Susana DE LA SIERRA (coords.) (Barcelona: Marcial Pons, 2009), 155 y ss.

${ }^{22}$ Para Luis ARROYo JiMÉNEZ, «...ponderación y proporcionalidad no son instituciones homogéneas. Por un lado, la primera es un método decisorio característico de determinados contextos normativos, caracterizados por un conflicto de normas que no se puede resolver mediante el establecimiento de una relación de preferencia incondicionada. Por otro lado, la segunda es esencialmente un método de control cuya aplicación presupone que la decisión objeto de control ha sido ya adoptada. La propia estructura del principio de proporcionalidad consiste, en efecto, en la aplicación del conocido test tripartito sobre una medida determinada, adoptada de ordinario por un sujeto distinto a aquel que desarrolla el juicio de control... ponderación es un método de decisión, mientras que el juicio de proporcionalidad es un método de control». (La cursiva, fuera del texto original) Véase, Luis ArRoYo JiMÉNEZ, «Ponderación, proporcionalidad y derecho administrativo...», 3334. Igualmente, Blanca RodríGuez RuIZ, «El caso 'Valenzuela Contreras' y nuestro sistema de derechos fundamentales» en Revista Española de Derecho Constitucional, n. ${ }^{\circ}$ 56, (1999): 233 y ss.

${ }^{23}$ Este es el perfil que le ha dado Carlos Bernal Pulido en su obra, El principio de proporcionalidad y los derechos fundamentales..., 566. También Daniel SARMIENTO, «El principio de proporcionalidad y la defensa de la autonomía local», en Revista de administración pública, $.^{\circ} 162,(2003), 170$ y ss. 
Para lo que interesa, ponderación se identificará con proporcionalidad en sentido estricto, esto es, como un subprincipio del principio de proporcionalidad en sentido amplio con todas sus máximas ${ }^{24}$.

Así, la ponderación y su núcleo, -la «ley de la ponderación»- que lo explica y lo fundamenta desde sus reglas como expresión de racionalidad, constituiría una parte integrante del principio de proporcionalidad en sentido amplio en el marco del control abstracto ${ }^{25}$. Es decir, una parte del gran argumento de la proporcionalidad en sentido amplio que opera en la fundamentación externa de la premisa mayor de las sentencias sobre el control de constitucionalidad de la ley ${ }^{26}$.

Esto se explica, según Alexy, por el hecho de que los subprincipios de idoneidad y necesidad que integran el test de proporcionalidad, «expresan el mandato de optimización relativo a las posibilidades fácticas, en los cuales las ponderación como método no juega ningún papel»», en tanto que, «el principio de proporcionalidad en estricto sentido se refiere a la optimización de las posibilidades jurídicas. Este es el campo de la ponderación $\rangle^{28}$.

Quizá, es en los casos de control concreto, donde pueden comparecer derechos en conflicto, que se representa la virtualidad más apreciable del juicio de

${ }^{24}$ En términos de José Juan Moreso es en el principio de proporcionalidad en estricto sentido donde la ponderación ocupa propiamente su lugar. Véase, José Juan Moreso, Alexy y la aritmética de la ponderación..., 71. Igualmente, Markus Gonzáles Beilfus, en una referencia a Rodríguez de Santiago, indica que la ponderación tiene entrada en el tercer requisito de la proporcionalidad, es decir, en la proporcionalidad en estricto sentido. Véase, GonZÁlez BeILfus, El principio de proporcionalidad en la jurisprudencia del Tribunal Constitucional..., 84. De hecho, la LOGJCC parece tratarlos como dos métodos diferentes o autónomos previstos en dos numerales distintos (2 y 3 ) del art. 3 de la ley; sin embargo, una lectura detenida y atenta confirma que la ponderación como método se identifica también con el subprincipio o subjuicio de la proporcionalidad: el de proporcionalidad en estricto sentido, lo que explica el grado de prevalencia de un derecho siempre que exista un debido equilibrio entre la protección y la restricción constitucional.

${ }^{25}$ Según José María Rodríguez de Santiago, «junto a la ponderación como tercer requisito del principio de proporcionalidad aparecen supuestos de aplicación del método de la ponderación no incluidos en el campo de proyección de aquel principio por faltar el elemento de la intervención del poder en la libertad del individuo. Son especialmente los casos de conflicto entre derechos individuales: libertad de información veraz de un periodista frente a derecho al honor de otro ciudadano; ... - etc.--》. Véase, José RoDRíGUEZ DE SANTIAGo, La ponderación de bienes e intereses en el Derecho Administrativo, (MadridBarcelona: Marcial Pons, 2000), 109.

${ }^{26}$ Carlos Bernal Pulido, El principio de proporcionalidad y los derechos fundamentales..., 566.

${ }^{27}$ Robert AlEXY, «La fórmula del peso» en El principio de proporcionalidad y la interpretación constitucional, ed. Por Miguel CARBonell (Quito: Ministerio de Justicia y Derechos Humanos, 2008), 15.

${ }^{28}$ Ibíd. 
ponderación constitucional ${ }^{29}$. Sin embargo, lo que se ponderará en el caso del control abstracto como una ejecución o puesta en práctica del subprincipio de proporcionalidad en estricto sentido, que no es sino un mandato de ponderación $^{30}$, «no es el derecho fundamental intervenido, con la ley que lo afecta sino, el derecho fundamental con la disposición constitucional, -otro derecho fundamental- que constituye el fundamento de la ley de intervención ${ }^{31}$, acudiendo a un agotamiento óptimo del sentido normativo de los principios en pugna bajo la consideración atenta de las circunstancias del caso $^{32}$.

Así, no se pretende ubicar en un mismo nivel de comparación los derechos fundamentales contenidos en la Constitución frente a normas infraconstitucionales, sino, todo lo contrario, ser congruentes con el mismo nivel de jerarquía de los derechos fundamentales en aras de una aplicación racional del principio de proporcionalidad en el marco de la unidad y sistematicidad constitucional $^{33}$.

${ }^{29}$ Quizá Prieto Sanchís lleve razón en el hecho de que «...la virtualidad más apreciable de la ponderación quizá no se encuentre en el enjuiciamiento abstracto de leyes, sino en los casos concretos donde se enjuician comportamientos de los particulares o de los poderes públicos». Sin embargo, para nuestro análisis, la ponderación importa como un componente del principio de proporcionalidad en sentido amplio para enjuiciar la labor del legislador democrático. Véase, Luis PRIETO SANCHÍs, «El juicio de ponderación constitucional» en El principio de proporcionalidad y la interpretación constitucional, ed. por Miguel Carbonell, (Quito: Ministerio de Justicia y Derechos Humanos, 2008) 106. Por otro lado, el mismo Luis Prieto Sanchís llama la atención sobre el distinto modo en el que el juicio de ponderación puede entra a operar. Así, uno es el ámbito de la esfera pública y, otro, el de la esfera privada, y dice: «En la primera se muestra lógicamente más riguroso... En cambio, en los conflictos entre derechos de particulares creo que la ponderación se reduce a este último tramo de la proporcionalidad en sentido estricto». Véase, Luis Prieto SANCHís, «Diez argumentos sobre neoconstitucionalismo, juicio de ponderación y derechos fundamentales», en Ponderación y Derecho Administrativo, ed. Por Luis ORTEGA y Susana DE LA SIERRA (coords.) (Madrid: Marcial Pons, 2009), 70.

${ }^{30}$ Daniel SARMIENTO, «El principio de proporcionalidad y la defensa de la autonomía local» en Revista de administración pública, n. ${ }^{\circ} 162$ (2003): 170.

${ }^{31}$ Bernal Pulido, El principio de proporcionalidad y los derechos fundamentales..., 486.

${ }^{32}$ Klaus GUNTHER, «Un concepto normativo de coherencia para una teoría de la argumentación jurídica», en Doxa. Cuadernos de Filosofía del Derecho, n. ${ }^{\circ}$ 17-18, (1995): 291 y ss. trad. Juan Carlos Velasco.

${ }_{33}$ Un claro ejemplo que confirma nuestra afirmación constituye el fallo de la Corte Constitucional ecuatoriana 048-13-SCN-CC de fecha 04/09/2013 en donde, mediante una consulta de constitucionalidad de la Ley Reformatoria al Título V, libro II del Código Orgánico de la Niñez y la Adolescencia y la Tabla de pensiones alimenticias mínimas expedidas por el Consejo Nacional de la Niñez y la Adolescencia, el órgano jurisdiccional, con el fin de resolver el caso en cuestión, identifica como principios en colisión, primero, la vida digna de los niños, niñas y adolescentes, el interés superior del menor, la 
Parece clara entonces, la existencia de una relativa independencia conceptual de los términos, puesto que, como tercer subprincipio o escalón del principio de proporcionalidad en sentido amplio, la ponderación forma parte de éste, aunque no se confunde con él en su integridad ${ }^{34}$.

Conviene decir en este momento que, la Corte Constitucional ecuatoriana ha abordado de forma poco precisa el tema de la relación existente entre el principio de proporcionalidad y el método de la ponderación. Aun cuando el órgano jurisdiccional indicó que su utilización e invocación no necesariamente implica que estos conceptos puedan analizarse de manera desarticulada, de manera poco consistente, indicó también que, «como métodos de interpretación, ambos constituyen instrumentos puestos a disposición de la jueza o juez constitucional para dilucidar el contenido de la norma fundamental $»^{35}$. Es decir, la Corte jamás definió de forma clara el alcance de dicha relación y su vinculación con la teoría de los derechos fundamentales y la interpretación constitucional ${ }^{36}$.

Por lo demás, el principio de proporcionalidad en sentido amplio, como principio jurídicamente exigible, es esencialmente un concepto relacional ${ }^{37}$ que carece de vida propia, ligado siempre a un sustrato normativo ${ }^{38} \mathrm{y}$ vinculado a una determinada teoría de la interpretación.

igualdad y la seguridad jurídica los mismos, que son deducidos como principios que se derivan de la ley en cuestión; y, segundo, la vida digna del alimentante, como el otro derecho fundamental en pugna. Consecuentemente, dicha colisión de principios, a pesar de que lo que se cuestiona es una ley, no se produce, como podría pensarse erróneamente, entre el derecho fundamental intervenido en forma de principio y la ley que lo afecta, sino entre el derecho fundamental intervenido y la disposición constitucional, otro derecho fundamental, que constituye el fundamento de la ley de intervención.

34 José Rodríguez de SANTIAgo, La ponderación de bienes e intereses en el Derecho Administrativo, (Madrid-Barcelona: Marcial Pons, 2000), 109.

35 Puesto que, el juicio de ponderación no constituye en estricto sentido un método de interpretación sino una técnica argumental o de fundamentación para resolver el conflicto entre derechos de la misma jerarquía. Véase, la sentencia de la Corte Constitucional ecuatoriana 048-13-SIN-CC, de fecha 04/09/2013.

${ }_{36}$ Por el contrario, a pesar de haberse enunciado en su sentencia un epígrafe destinado al análisis de «el principio de proporcionalidad y la ponderación en el ordenamiento ecuatoriano», la Corte diluye su argumentación indicando que la intención de los consultantes es que se «dilucide una pretendida colisión entre principios constitucionales, por medio de la utilización del método de interpretación denominado test de proporcionalidad» lo cual, poco ha contribuido a aclarar el tema, así como a arrojar luces sobre el alcance y relación entre uno y otro concepto. Véase, la sentencia indicada, 048-13-SIN-CC, de fecha 04/09/2013.

37 En el sentido de que compara dos magnitudes: medios y fines. Véase, BARNÉs, El principio de proporcionalidad. Estudio preliminar..., 15-49.

${ }^{38}$ Ibíd., p. 17. Un sustrato normativo que relaciona una norma expedida por el legislador frente a un derecho fundamental. 
Se trata de una pieza dentro de un sistema, de un universo más amplio en el que se enmarca y al que pertenece, como el que encarnan la teoría general de los derechos fundamentales, las técnicas de control judicial, el canon de constitucionalidad, etc. ${ }^{39}$

Ahora bien, el principio de proporcionalidad en sentido amplio se encuentra integrado por un conjunto de herramientas que permiten medir la licitud de toda intervención de género normativo en el ejercicio de los derechos desde un concreto perfil, que es evitar la inutilidad, necesidad, desequilibro o desproporción de una medida empleada ${ }^{40}$.

Según criterio de algunos autores, el principio de proporcionalidad constituye también uno de los límites a la limitación de los derechos ${ }^{41}$, comúnmente empleado en el ámbito del control de constitucionalidad para definir el ámbito de validez de una medida normativa utilizada en relación con un fin propuesto. Una barrera frente a intromisiones indebidas en el ámbito del ejercicio de los derechos fundamentales.

El principio de proporcionalidad también es conocido en la doctrina y en la jurisprudencia como proporcionalidad de los medios, proporcionalidad del sacrificio, proporcionalidad de la injerencia, prohibición de exceso ${ }^{42}$, etc., entre otras denominaciones expresivas de la idea de moderación, como límite a la esfera de la libertad del legislador democrático ${ }^{43}$.

\section{ESTRUCTURA DEL PRINCIPIO DE PROPORCIONALIDAD}

Varios son los trabajos que exploran la aplicación del principio de proporcionalidad, de los juicios que la integran y de sus posibilidades y límites

39 Ibíd., p. 15.

${ }^{40}$ Ibíd., p. 16.

${ }^{41}$ El concepto de límite de los límites se refiere a aquellos límites que deben observarse cuando se interfieren en el campo de los derechos, es decir un resultado de la estructura tríadica idoneidad, necesidad y proporcionalidad, a la que se deben someter las limitaciones de los derechos. Véase, Laura CLÉRICO, El examen de proporcionalidad en el derecho constitucional, (Buenos Aires: Eudeba, 2009), 23. También Miguel Carbonell se ha referido al principio de proporcionalidad como el límite de los límites a los derechos fundamentales. Véase, Miguel CARBONell, El principio de proporcionalidad y la interpretación constitucional (Quito: Ministerio de Justicia y Derechos Humanos, 2008), 10.

${ }^{42}$ Teresa Aguado Correa indica que, aunque actualmente no se discute en la doctrina alemana sobre la exigencia de respecto de este principio por parte de los poderes públicos; legislativo, ejecutivo y judicial, puesto que se trata de un principio general del ordenamiento jurídico que abarca todos los ámbitos del Derecho, sobre lo que no existe unanimidad en el seno de la doctrina alemana es sobre la denominación y el contenido del principio. Véase, Teresa AGUADo CORREA, El principio constitucional de proporcionalidad, (San José: Editorial Jurídica Continental, 2013), 55-56.

${ }_{43}$ Javier BARNÉs, El principio de proporcionalidad. Estudio preliminar..., 19. 
como instrumento de control de diversas intervenciones sobre los derechos fundamentales ${ }^{44}$.

Sin embargo, conviene recordar la estructura básica del principio o test de proporcionalidad en sentido amplio, implementado mediante la formulación de los tres criterios escalonados, máximas o subprincipios que lo integran: idoneidad o adecuación, necesidad y proporcionalidad en estricto sentido ${ }^{45}$.

Según el subprincipio de idoneidad, toda intervención en los derechos fundamentales debe ser adecuada para contribuir a la obtención de un fin constitucionalmente legítimo, excluyéndose la adopción de medios que no contribuyan a la realización de los fines para los cuales han sido $\operatorname{adoptados}^{46}$.

No se trata aquí de suplantar al legislador democrático y de imponer el medio más idóneo, sino tan sólo de excluir aquellos que resulten ineficaces

${ }^{44}$ Entre la extensa bibliografía disponible conviene mencionar, entre otros, los trabajos de Robert ALEXY, Teoría de los derechos fundamentales, (Madrid: Trotta, CEPC, 2001); Robert AlEXY, «Epílogo a la Teoría de los Derechos Fundamentales», en Revista Española de Derecho Constitucional, 66, (2002), 13-64 trad. Carlos Bernal Pulido; Carlos BERnAl PUldDo, El principio de proporcionalidad y los derechos fundamentales, (Madrid: CEPC, 2005); Laura CLÉRICO, El examen de proporcionalidad en el derecho constitucional, (Buenos Aires: Eudeba, 2009), 408; así como los trabajos incluidos en el volumen colectivo El principio de proporcionalidad y la interpretación constitucional, en Miguel CARBONELl (coord.), (Quito: Ministerio de Justicia y Derechos Humanos, 2008); o, Miguel CARbonell, El principio de proporcionalidad en el derecho comparado, (Lima: Palestra, 2010).

45 Véase, Robert AlEXY, «Los derechos fundamentales y el principio de proporcionalidad» en Revista Española de Derecho Constitucional, n. ${ }^{\circ}$ 9, (2011): 11-29; Manuel MEDINA Guerrero, La vinculación negativa del legislador a los derechos fundamentales, (Madrid: Mc Graw Hill, 1997), 120 y ss.; Javier BARNÉS, «El principio de proporcionalidad. Estudio preliminar» en Cuadernos de Derecho Público, n. ${ }^{\circ}$ 5, (1998): 15 y ss.; Carlos BERnAl Pulido, El principio de proporcionalidad y los derechos fundamentales, (Madrid: Trotta, 2005), 37 y ss.; Gloria LOPERA MESA, «Principio de proporcionalidad y control constitucional de las leyes penales. Una comparación entre la experiencias de Chile y Colombia», en Revista de Derecho Valdivia, vol. XXIV n. ${ }^{\circ}$ 2, (2011): 114 y ss.; Markus GonzÁlez BeILfus, El principio de proporcionalidad en la jurisprudencia del Tribunal Constitucional, 2da. ed., (Navarra: Aranzadi-Thomson, 2015), 48 y ss.; Laura ClÉRICO, El examen de proporcionalidad en el derecho constitucional, (Buenos Aires: Eudeba, 2009).

46 Robert Alexy, «Los derechos fundamentales y el principio de proporcionalidad» en Revista Española de Derecho Constitucional, n. ${ }^{\circ} 9$ (2011), 13. Conviene precisar, conforme sostiene el propio Alexy, que, casos en los cuales se ha declarado inconstitucional una ley a causa de su inidoneidad son poco frecuentes. Normalmente, el medio adoptado por el legislador buscará, por lo menos, realizar sus fines en alguna medida. Esto basta para superar el test de idoneidad. 
con el fin de evitar una tensión entre corte y legislador ${ }^{47}$. Así, una medida que afecte a un derecho sólo es válida si es también funcionalmente idónea ${ }^{48}$.

Podría decirse que tampoco se exige que el fin perseguido tenga rango constitucional. El fin debe ser constitucionalmente legítimo, esto es, ha de caber dentro de las posibilidades de actuación que la Constitución permite al legislador ${ }^{49}$.

El subprincipio de necesidad, por su parte, se refiere a que toda medida de intervención en los derechos fundamentales debe ser la más benigna con el derecho intervenido entre aquellas que revisten la misma idoneidad para alcanzar el objetivo buscado. Dicho en otras palabras, lo que este subprincipio exige es que de entre dos medidas igualmente idóneas respecto a un principio, se escoja la menos levisa al derecho intervenido ${ }^{50}$.

La medida restrictiva no sólo debe ser idónea para limitar el derecho en razón de su fundamento; además, entre las posibles maneras de imponer la medida restrictiva, sólo cabe elegir la forma o el medio que resulte menos gravoso para alcanzar aquella finalidad propuesta ${ }^{51}$.

Debe señalarse que, en el caso del legislador, y por su especial posición constitucional dentro del ordenamiento constitucional, la densidad del control con respecto a la necesidad es más reducida, en la medida en la que la elección de una alternativa en lugar de otra suele entrar a formar parte del margen de libre configuración legislativa ${ }^{52}$.

${ }^{47}$ Como lo dice textualmente Prieto SAnchís: «Ciertamente, no queda del todo claro si el fin perseguido con la norma o actuación enjuiciada ha de coincidir precisamente con un principio o valor constitucional o basta cualquiera que no esté proscrito. En línea de principio, pudiera pensarse que la ponderación se establece entre normas del mismo nivel jerárquico, es decir, entre fines con igual respaldo constitucional, pero creo que en la práctica puede existir una deferencia hacia el legislador, un respeto hacia su autonomía política -que, en verdad, constituye en sí misma un valor constitucional-de manera que se acepten como fines legítimos todos aquellos que no estén prohibidos por la Constitución o resulten abiertamente incoherentes con su marco axiológico. Véase, Luis PRIETO SANCHÍs, «El juicio de ponderación constitucional...», p. 109.

48 Ignacio ViLLAVERDE, «La resolución de conflictos entre derechos fundamentales. El principio de proporcionalidad» en El principio de proporcionalidad y la interpretación constitucional, ed. Por Miguel Carbonell (Quito: Ministerio de Justicia y Derechos Humanos, 2008), 184.

49 GonzÁlez BeILfus, El principio de proporcionalidad en la jurisprudencia del Tribunal Constitucional..., 49.

50 ALEXY, Los derechos fundamentales y el principio de proporcionalidad..., 14.

${ }^{51}$ VILLAVERDE, ¿Existen los conflictos entre derecho fundamentales? ¿Ponderación de bienes o delimitación de los derechos?..., 184.

${ }_{52}$ BeILfus, El principio de proporcionalidad en la jurisprudencia del Tribunal Constitucional..., 51 . 
Finalmente, el subprincipio de proporcionalidad en estricto sentido -ponderación- es aquel que se orienta a guardar una adecuada relación entre el derecho intervenido y el derecho satisfecho. En otras palabras, las ventajas que se obtengan con la medida deben compensar los sacrificios que aquella comporta para algún derecho.

Tal como lo ha referido Alexy:

La optimización relativa a las posibilidades fácticas consiste en ahorrar costos que pueden ser evitados. Sin embargo, los costos devienen en inevitables si los principios entran en conflicto. La ponderación entonces se hace necesaria. La ponderación es el tema del tercer subprincipio del principio de proporcionalidad, esto es, el principio de proporcionalidad en sentido estricto ${ }^{53}$.

A diferencia de los pasos anteriores, éste último escalón o paso, entraña más bien un juicio normativo o jurídico que no trata de indagar si en la práctica, o desde un punto de vista técnico, la medida es idónea o si existe otra menos gravosa, «sino de valorar el grado de afectación o lesión de un principio, el grado de importancia o urgencia en la satisfacción de otro y, por último, a la luz de todo ello, de valorar la justificación o falta de justificación de la medida en cuestión $\rangle^{54}$.

Se trata, en último término, como señala Díez Ripollés en el marco del Derecho penal, «de evitar un desequilibrio patente, excesivo o irrazonable entre los fines perseguidos y los medios empleados, de modo que el derecho o los derechos fundamentales afectados por la pena no sean objeto de un sacrificio injustificado ${ }^{55}$.

Estos tres subprincipios expresan en su conjunto la idea de optimización $^{56}$. Cada uno de los criterios o máximas (utilidad, necesidad y proporcionalidad en sentido propio o estricto o «ponderación») requieren de un análisis diverso en su aplicación.

De alguna manera «todos juzgan la relación de medio a fin, pero bajo un perfil diferente. El medio ha de ser idóneo para la consecución del objetivo; necesario -el más moderado- respecto de todos los medios útiles y susceptibles de alcanzarlo; y razonable o proporcionada la ecuación costes-beneficios en su resultado ${ }^{57}$.

De lo dicho se evidencia que el principio de proporcionalidad no es estrictamente un juicio positivo con el fin de determinar si la intervención pública

53 ALEXY, Los derechos fundamentales y el principio de proporcionalidad..., 15.

54 Véase, PRIETO SANChís, El juicio de ponderación constitucional ..., 112.

55 José Luis DíEz RIPOLLÉs, «El control de constitucionalidad de las leyes penales» en Revista Española de Derecho Constitucional, n. ${ }^{\circ} 75$, (2005):88.

56 AlEXY, Los derechos fundamentales y el principio de proporcionalidad..., 13.

57 BARNÉs, El principio de proporcionalidad. Estudio preliminar..., 25. 
pudo ser más proporcionada o no. No sirve, pues, para medir o encontrar la solución más idónea, de mayor equilibrio del medio óptimo, sino sólo para cuestionar aquellas conductas normativas que se sitúen en el extremo inferior de la escala ${ }^{58}$.

Con todo, la afirmación anterior debe ser matizada en el ámbito del control abstracto de norma, puesto que si se entiende efectivamente que la Corte o Tribunal, una vez constatada la inconstitucionalidad de la disposición cuestionada puede hacer uso de las denominadas sentencias modulativas o manipulativas, se habría sobrepasado ese límite negativo del control tan cuestionado en los actuales momentos, para asumir un rol más activo-positivo en defensa de los derechos fundamentales.

Una adecuada concreción del principio de proporcionalidad por parte de la justicia constitucional contribuirá a la pretensión de corrección ${ }^{59}$ de las decisiones jurídicas adoptadas. Es decir, como parámetro o fuente de legitimidad de sus actuaciones frente a la tarea desplegada por el legislador.

La pretensión de corrección, necesariamente conectada con la jurisdicción constitucional en el marco de una teoría de la interpretación, exige que una decisión tomada por un tribunal sea tanto posible como racional. En tal virtud, la única forma de control de dicha racionalidad se hace posible mediante un control sobre la argumentación de la decisión.

El problema consistirá, entonces, en verificar en la motivación de las sentencias qué argumentos y criterios interpretativos centrales pueden constituirse en un marco válido para la utilización de dicho principio, al estar provistos de un grado de racionalidad controlable y aceptable por un auditorio que se mira como destinatario de las decisiones jurídicas.

De lo contrario, el principio de proporcionalidad, y fundamentalmente su aplicación a los casos concretos, no sería más que una «composición salomónica $»^{60}$ en manos de los jueces que ahondaría la crítica a legitimidad democrática de las cortes, restringiendo indebidamente la libertad legislativa de configuración constitucional.

${ }^{58}$ Ibíd., pp. 28-29.

59 Una decisión judicial, si no formula o satisface una pretensión de corrección, es jurídicamente deficiente. A una pretensión jurídica de corrección corresponde un deber jurídico de satisfacerla en aras de ser correcta y susceptible de ser fundamentada. Así, una pretensión de corrección es un elemento necesario del concepto de Derecho. Véase, Robert AleXY, El concepto y la validez del derecho, (Barcelona: Gedisa, 1997), 41 y ss.

${ }^{60}$ Javier Jiménez CAMPO, Derechos fundamentales. Concepto y garantía, (Madrid: Trotta, 1999), 73. 


\section{EL PRINCIPIO DE PROPORCIONALIDAD COMO CANON DE CONSTITUCIONALIDAD: EL CASO ECUATORIANO}

Reconstruir y evidenciar el discurso de la Corte Constitucional ecuatoriana en sus sentencias para proceder luego con la interpretación de las mismas, analizando las relaciones de significado que el órgano de justicia constitucional reproduce o asigna a ciertas instituciones del Derecho, concretamente, al principio de proporcionalidad como canon del control de constitucionalidad y fuente de legitimidad, constituye la tarea fundamental de este apartado.

Para ello, resulta necesario recordar que, dado que el principio de proporcionalidad se relaciona con una noción de racionalidad lógico-operacional a través de la cual las Cortes y Tribunales desarrollan su actividad de control ${ }^{61}$, su exigencia en la fundamentación ha de estar provista de unas ideas claras en relación con su utilización y puesta en práctica, a afectos de convertirse en un canon de constitucionalidad controlable y, por tanto, en un mecanismo de fuente de legitimidad de la tarea jurisdiccional.

Ciertamente, en un ánimo de construir un parámetro de fundamentación racional de las decisiones adoptadas por la Corte, la introducción de la idea de proporcionalidad tanto por la Corte Constitucional de Transición-CCT-, como por la Primera Corte Constitucional del Ecuador - $\mathrm{CC}-$, ha sido cada vez más frecuente a la hora de justificar su intervención respecto de medidas adoptadas por el Legislador.

\subsection{Corte Constitucional de Transición}

A pesar que la Corte, al menos en materia de control abstracto de norma, ha esperado a la reciente sentencia 048-13-SCN-CC para aclarar el sentido general del principio de proporcionalidad en el ordenamiento jurídico ecuatoriano, manifestando que «en nuestro ordenamiento jurídico la proporcionalidad tiene dos sentidos distintos: constituye a la vez un principio reconocido en diversos artículos de la Constitución de la República pero también se configura como un método de interpretación constitucional constante en el artículo 3 de la Ley Orgánica de Garantías Jurisdiccionales y Control

${ }^{61}$ Bernal Pulido, El principio de proporcionalidad y los derechos fundamentales..., 491, manifiesta que la idea de racionalidad del principio de proporcionalidad se enmarca dentro del ámbito de la llamada racionalidad teórica de los conceptos jurídicos. Es decir, un tipo de racionalidad que enfatiza que los conceptos y las argumentaciones utilizadas por los teóricos del Derecho y por los Tribunales en la fundamentación de sus decisiones deben estar provistos de un elevado nivel de precisión. 
Constitucional, junto con el método de la ponderación ${ }^{62}$, dicho principio fue recogido ya en los primeros fallos del órgano jurisdiccional.

En sus inicios, la utilización del principio de proporcionalidad por parte de la jurisprudencia constitucional fue más bien informal e intuitiva, asociada vagamente a la idea de un nuevo modelo de Estado imperante desde la vigencia de la Constitución de 2008, lo cual no quiere decir que la proporcionalidad, como principio, no haya estado presente con anterioridad en el constitucionalismo ecuatoriano ${ }^{63}$.

Quizá, la recepción del principio de proporcionalidad por parte de la jurisprudencia constitucional, más allá de su positivización como norma, se vio impulsada por el desarrollo jurisprudencial que los tribunales internacionales

${ }^{62}$ Véase, sentencia de la Corte 048-13-SCN-CC, de fecha 04/09/2013, sobre la consulta de norma jurídica.

${ }^{63}$ Varias son las Constituciones ecuatorianas que han recogido el principio de proporcionalidad en su articulado, aun cuando en muchas de ellas el ámbito de referencia sería el fiscal. Por ejemplo, la Constitución de 1851, art. 113, Capítulo XIX de las Garantías, indica que «...en todo impuesto se guardará la proporción posible con los haberes de industria de los contribuyente»; la Constitución de 1852, art. 121, Título XI de las Garantías, establece igualmente que «...en todo impuesto se guardará la proporción con los haberes o industria de cada ecuatoriano»; la Constitución de 1861, art. 116, Título XI de las Garantías indica que «...en todo impuesto se guardará la proporción posible con los haberes e industria de cada persona». De forma idéntica, en la Constitución de 1869, art. 101, Título XI de las Garantías, se menciona que «...en todo impuesto se guardará la proporción posible con los haberes e industria de cada persona»; la Constitución de 1878 reproduce lo mismo en su art. 17, numeral 2, literal c) del Título II, Sección III; la Constitución de 1884, art. 26, Título IV de las Garantías, reitera, al igual que las anteriores, que «...en todo impuesto se guardará la debida proporción con los haberes e industrias del contribuyente»; la Constitución de 1897 lo vuelve a concebir en iguales términos en su art. 17, Título IV de las Garantías y la Constitución de 1906 lo recoge de la misma manera en su art. 17, Título V de las Garantías Nacionales. La Constitución de 1928 en sus disposiciones transitorias hace referencia a la proporción en materia de representación electoral; la Constitución de 1945, art. 23 se refiere igualmente a la representación proporcional en materia electoral, pero también habla en su art. 148, Sección V del Trabajo, que los trabajadores serán participes de las utilidades de las empresas en la forma y proporción que fije la ley; la Constitución de 1946 retoma en su art. 182, Título II de las Garantías, que «no se pueden crear impuestos u otros ingresos públicos sino en virtud de una ley y en proporción a la capacidad económica del contribuyente»; la Constitución de 1967, art. 71, vuelve sobre el tema de la representación proporcional en materia electoral, esta vez en referencia de las minorías, la Constitución de 1979, art. 34, habla igualmente de la representación proporcional a las minorías; la Constitución de 1998, art. 24, numeral 2, Capítulo II, avanza en consagrar como garantía del debido proceso el principio de proporcionalidad entre las infracciones y las sanciones en su art. 99 se refiere a la representación proporcional de las minorías y en su art. 256 relaciona la proporcionalidad con el régimen tributario. Así, hasta llegar a la Constitución de 2008, en donde, existen varias disposiciones relativas al principio de proporcionalidad. 
de derechos humanos o los instrumentos internacionales de derechos humanos han dado a otro principio básico: el de igualdad, muy ligado a una idea de proporcionalidad $^{64}$.

Así, aunque la Corte Constitucional para el período de Transición acudió tempranamente a la idea de proporcionalidad en el marco del control abstracto de norma, su invocación en las sentencias adoptadas fue descriptiva y general, dirigida a interpretar otros principios fundamentales como el de la igualdad.

En efecto, en la sentencia 002-09-SIN-CC, en el cual se demandó la inconstitucionalidad de la Ley para Reprimir el Lavado de Activos, en relación con los requisitos para poder acceder al cargo de director general y subdirector de la Unidad de Inteligencia Financiera, la CCT abordó de manera poco consistente el principio de proporcionalidad y lo vinculó de forma directa con el principio de igualdad.

En el caso en referencia, la Corte indicó: «En relación al principio de igualdad, no se ha verificado la vulneración acusada, pues los destinatarios de la ley requieren el reconocimiento de la diferencia, ya que la generalidad del acceso al cargo público es la profesión; sin embargo, la medida legislativa aquí cuestionada es proporcional ya que exige la verificación de tres supuestos... En ese orden de ideas, satisfacen los parámetro de razonabilidad y proporcionalidad, aquellos límites que inequívocamente permiten asegurar la realización de los principios que orientan la función pública».

Es decir, en este caso, la Corte no sólo invirtió el orden lógico de su argumentación, al afirmar, primero, que la norma cuestionada era proporcional, para luego indicar los «tres supuestos»-como lo llama inicialmente la

${ }^{64}$ Puede verse, por ejemplo, en la sentencia de la Corte 022-12-SIN-CC, p. 25, de fecha 07/06/2012, donde se hace una referencia al principio de igualdad tomada del voto salvado del juez A. Cancado Trindade en el caso Acosta Calderón vs. Ecuador de la Corte Interamericana de Derechos Humanos. También la sentencia 027-12-SIN-CC, pp. 1112, de fecha 21/06/2012, en la que se recurre a la Convención Americana de Derechos Humanos de 1969, a la Declaración de los Derechos del Hombre y del Ciudadano de 1789 y a la Convención Internacional sobre la eliminación de todas las formas de discriminación racial, ratificada por la Asamblea General de la ONU en 1965, para referirse al principio de igualdad. En la Primera Corte Constitucional se pueden encontrar casos como la sentencia 015-15-SIN-CC, p. 13, de fecha 29/04/2015, en la cual se hace una referencia a la Corte Interamericana de Derechos Humanos, así como al Tribunal Europeo de Derechos Humanos, en relación con el Convenio para la Protección de los Derechos Humanos y de las Libertades Fundamentales, para desarrollar el principio de igualdad en relación con una idea de proporcionalidad. Asimismo la sentencia de la Corte Constitucional 006-14-SIN-CC, p. 13, de fecha 24/09/2014, donde, para dotar de contenido al principio de igualdad, se recurrió a la misma referencia, a la Corte Interamericana de Derechos Humanos así como al Tribunal Europeo de Derechos Humanos, en relación con el Convenio para la Protección de los Derechos Humanos y de las Libertades Fundamentales. 
Corte- que integran el juicio de proporcionalidad, sino que, además, no diferenció el principio de proporcionalidad de una idea general de razonabilidad y lo vinculó al análisis del principio de igualdad.

Conviene destacar que esta sentencia sentó lo que sería una constante en las decisiones de la Corte, consistente en admitir, que es al legislador en ejercicio de su autonomía, a quien corresponde configurar con criterios de oportunidad y conveniencia el ejercicio de los derechos, lo cual será confirmado en una serie de casos siguientes tanto por la Corte de Transición, como por la Primera Corte Constitucional ${ }^{65}$.

Ahora bien, independientemente de dichas referencias, la concreción de una idea de proporcionalidad como principio interpretativo, ha sido más bien confusa y tan solo enunciativa a lo largo varias sentencias emitidas por el órgano jurisdiccional.

Así, por ejemplo, en ninguna de las sentencias citadas, la Corte desarrolló un estándar estricto de aplicación del principio de proporcionalidad con los subjuicios que lo integran. Más bien, se lo utilizó de forma imprecisa y general, relacionándolo directamente con el principio de igualdad y/o razonabilidad $^{66}$.

En efecto, conforme se ha venido evidenciando, el principio de proporcionalidad tiene un carácter relacional, en el sentido de que no es predicable de una actuación considerada aisladamente ${ }^{67}$. La proporcionalidad se articula, siempre, en torno a una relación que supone un medio utilizado y un fin propuesto.

Es decir, se trata de un principio de medio-fin que se diferencia de otros principios interpretativos, entre ellos, los de la razonabilidad, concordancia práctica $^{68}$, igualdad y ponderación como juicio autónomo.

${ }_{65}$ Véase, la sentencia de la Corte Constitucional 002-09-SIN-CC, de fecha $14 / 05 / 2009$. Dicho reconocimiento es ratificado en varias sentencias de la Corte, por ejemplo, los fallos: 002-10-SIN-CC, de fecha 08/04/2010; 007-10-SIN-CC, de fecha 15/07/2010; 002-011-SIN-CC, de fecha 21/06/2011; 003-11-SIN-CC, de fecha 21/06/2011; 010-12-SIN-CC, de fecha 17/04/2012; 019-12-SIN-CC, de fecha 26/04/2012; 007-13-SIN-CC, de fecha 25/03/2013; 008-13-SIN-CC de fecha 13/06/2013; 010-13-SINCC, de fecha 25/09/2013.

${ }^{66}$ En la sentencia 017-12-SIN-CC, de fecha 26/04/2012, la Corte, haciendo uso de la institución del precedente constitucional, se refirió a un criterio de razonabilidad ligado al concepto de igualdad.

${ }^{67}$ GonzÁlez BeILfuss, El principio de proporcionalidad en la jurisprudencia del Tribunal Constitucional..., 81.

${ }_{68}$ A este respecto, para Bernal Pulido «...el principio de proporcionalidad en sentido amplio y sus subprincipios no se oponen a la concordancia práctica, sino que por el contrario, son un medio para hacerla efectiva» en la medida en la que, a pesar de que el resultado de la aplicación del principio de proporcionalidad consiste en la atribución de carácter definitivo a las normas o posiciones que se adscriben a uno de los derechos 
De lo dicho, se desprende que cuando la CCT ha invocado el principio de proporcionalidad en sus sentencias, lo ha hecho de forma muy precaria y genérica, revelando la poca claridad del concepto en el ámbito de su aplicación práctica.

Otro caso patente de falta de definición del principio de proporcionalidad en la jurisprudencia de la CCT es la sentencia 005-09-SIN-CC, en la que el ejercicio del control abstracto de norma recayó sobre un Decreto Ejecutivo de declaratoria de estado de excepción. Debido a que la Constitución de la República indica que el estado de excepción debe observar entre otros, los principios de proporcionalidad y razonabilidad ${ }^{69}$, lo cual le habría permitido concretar el alcance de cada principio en relación con una situación excepcional ${ }^{70}$, así como una oportunidad precisa para ejercer el control sobre los excesos de poder que afectan a los derechos fundamentales, asegurando, la fuerza normativa de la Constitución, sin embargo, en el voto de mayoría no hubo mayor análisis respecto del principio de proporcionalidad, más allá de la cuestionada referencia a una relativización del principio de temporalidad, en función, dijo la Corte, de su excepcionalidad, necesidad y proporcionalidad ${ }^{71}$, permitiendo que dichas declaratorias de excepción se extiendan en el tiempo más allá de lo previsto constitucionalmente.

La amplia discrecionalidad de valoración con la que la Corte ha interpretado y aplicado el principio de proporcionalidad resulta patente. Esto es especialmente evidente, en su jurisprudencia inicial, en la que la alusión a dicho principio no pasa de ser un mero enunciado general y disperso, sin mayor concreción, análisis o aportación que ayude a dotar de contenido al mismo.

En la dimensión más clásica del principio de proporcionalidad, como es la relativa a las sanciones en relación con las infracciones, la Corte, en el fallo 004-12-SIN-CC que se refiere a una impugnación de una Ordenanza Metropolitana que sancionaba el uso de suelo por parte de los vehículos

fundamentales en conflicto, dicha consecuencia solo es posible hacerla efectiva si se tienen en consideración unos derechos que se encuentran en igualdad de condiciones. Véase, BERNAL PULIDO, El principio de proporcionalidad y los derechos fundamentales..., 557.

${ }^{69}$ Véase, el art. 164 inciso 2 de la Constitución de la República del Ecuador de 2008.

${ }^{70}$ Aun cuando en la figura de estado de excepción está clara la conexión de los principios a ser controlados.

${ }^{71}$ Un análisis interesante respecto de la instrumentalización de los estados de excepción por parte del Ejecutivo, así como del deficiente control de constitucionalidad sobre los mismos, puede verse en Agustín GriJalva, Elsa Guerra y Dunia Martínez, «Límites constitucionales al poder ejecutivo» en Derecho Constitucional e instituciones politicas. Derechos humanos y justicia constitucional. Ensayos en honor el Prof. Hernán Salgado $P$., (Quito: Corporación de estudios y publicaciones, 2015), 99 y ss. 
privados, se limitó a indicar que la norma cuestionada no transgredía dicho principio.

Consecuentemente, en el caso analizado, a la Corte le bastó decir que no existía falta de proporcionalidad entre la infracción cometida y la sanción administrativa impuesta por los municipios respecto de las normas que regulan el uso de suelo ${ }^{72}$, sin desarrollar ningún test de proporcionalidad tendente a justificar tal posición, e independientemente de otros argumentos que hubiera podido aportar el órgano control constitucional.

En el mismo sentido, en la sentencia 010-12-SIN-CC, la CCT indicó que procedería a realizar un análisis de la norma impugnada, -Ley de Impuestos para la Junta de Beneficencia de Guayaquil-, con el fin de determinar si la medida impositiva de carácter tributario que contenía era proporcional. Sin embargo, el anunciado ejercicio interpretativo, en realidad, no pasó de una simple fórmula retórica, sin que se desarrollara una concreción del principio y de su aplicación. Es decir, en este caso no se realizó ningún test de proporcionalidad de la medida enjuiciada que hubiera llevado a la convicción razonable y controlable de la Corte de que tal medida no era desproporcional y, en consecuencia, era conforme a la Constitución ${ }^{73}$.

Cosa similar ocurrió en la sentencia 005-12-SIN-CC, en la que de forma genérica y enunciativa, frente a una demanda de impugnación de un acuerdo ministerial que imponía un pago de registro a las empresas de vigilancia y seguridad privada, analizando el ejercicio del derecho a desarrollar una actividad económica-empresarial, la Corte sostuvo: «...La interpretación proporcional de este derecho nos conduce a observar que el requisito de pago por concepto de gastos administrativos no restringe la actividad empresarial

${ }^{72}$ En este fallo, la Corte sostuvo: «...los municipios, a través de las ordenanzas, expiden normas por las cuales regulan aspectos relacionados con sus atribuciones y competencias, disponiendo las sanciones que correspondan por la inobservancia o transgresión de tales normas, dependiendo también de la gravedad de las mismas (por ejemplo no contar con permisos de funcionamiento de locales comerciales, construir o efectuar reparaciones a los inmuebles sin contar con los planos y permisos respectivos, lotizar terrenos sin contar con la autorización y permisos correspondientes, etc.); por tanto, la sanción administrativa que impone el Municipio del Distrito Metropolitano de Quito, por estacionar vehículos en lugares prohibidos, en contravención de las normas que regulan el buen uso del suelo, no transgrede el principio de proporcionalidad ente infracción y sanción».

${ }^{73}$ En esta sentencia, la Corte manifestó: «Frente a aquello, esta Corte debe realizar un ejercicio de interpretación constitucional en donde determine si la medida impositiva es proporcional con el objeto y finalidad para el cual está destinado este impuesto. Al respecto, se colige que el impuesto en cuestión resulta absolutamente necesario y legitimo a la luz de todos los servicios sociales que presta la Junta de Beneficencia de Guayaquil...es decir, por medio de este impuesto la sociedad se ve ampliamente retribuida, por tanto la medida adoptada es completamente proporcional y guarda armonía con el marco constitucional al propender la protección de varios derechos sociales...». 
de las compañías de vigilancia y seguridad privada, ya que al establecer un costo por la actividad administrativa de registro no se está coartando el ejercicio del derecho a la libertad de empresa, sino que se protege el interés de la sociedad en la regulación de las actividades en las que se encuentra comprometida la seguridad interna del Estado ${ }^{74}$.

Independientemente de lo acertado o no de la decisión adoptada, tampoco en el caso en mención se estructuró un test de proporcionalidad que integrara en debida forma los juicios de idoneidad, necesidad y proporcionalidad en sentido estricto. Y sin embargo, una adecuada utilización del principio de proporcionalidad es lo que puede hacer de éste, un parámetro de control objetivo de mayor calidad.

En alguna otra ocasión, como, por ejemplo, en la sentencia 011-12-SIN$\mathrm{CC}$, cuando la Corte indicó que una resolución del Consejo Nacional Electoral que exige la presentación del certificado de haber sufragado no limita el ejercicio de los derechos, ni impone una exigencia injustificada que genere una desigualdad salvo el caso de los trámites jurisdiccionales, se pudo haber recurrido a una aplicación racional y controlable del principio de proporcionalidad para reforzar el razonamiento del órgano jurisdiccional, no obstante, la argumentación no se encaminó en dicho sentido. Es decir, las referencias genéricas primaron en la argumentación de la Corte.

Este uso poco depurado y más bien intuitivo y discrecional de la aplicación del principio de proporcionalidad durante los primeros años de la Corte también generó una falta de claridad sobre aspectos dogmáticos de la teoría general de los derechos, dada la importancia que, a pesar de todo, el órgano de justicia constitucional, en ocasiones, ha dado a la proporcionalidad en relación con la tutela de ciertos derechos fundamentales, principalmente, el principio de igualdad, tal como se indicó anteriormente.

El uso de una retórica dispersa y confusa ha contribuido a que la Corte no mantenga una definición consistente del principio de proporcionalidad y de otros elementos de la teoría general de los derechos.

Al margen de lo anotado, un esfuerzo interesante por desarrollar el contenido y el sentido del principio de proporcionalidad con los subjuicios que lo integran, es decir, de concreción del contenido normativo del principio, lo constituye la sentencia 002-11-SIN-CC, en la que se resolvió sobre la constitucionalidad de Ley del Sistema Nacional de Registro de Datos Públicos ${ }^{75}$.

74 Véase, la sentencia de la Corte 005-12-SIN-CC, p. 14, de fecha 29/04/2012.

75 En esta sentencia, la Corte entró a conocer algunos problemas relativos a la demanda de inconstitucionalidad, tanto formal como material. En la forma, se cuestionó por parte del legitimado activo: 1) La finalidad de la ley, ya que la misma, a su juicio, debía tener el carácter de orgánica, 2) Que la iniciativa fuera exclusiva del Presidente de la República, 3) El respeto al principio de unidad de la materia, al haber regulado en un solo 
En dicha sentencia, luego de una enunciación poco favorable al uso método tópico así como al principio de unidad constitucional y del criterio de interpretación finalista, la Corte indicó que procedería al análisis de la norma impugnada sobre la base de «un test de razonabilidad y proporcionalidad» $\rangle^{76}$.

Efectivamente, en este caso, la CCT identificó por separado lo que llama un test de razonabilidad y un test de proporcionalidad ${ }^{77}$, desarrollando en el marco del control abstracto de norma, los subjuicios o subprincipios del principio de proporcionalidad, frente a la imprecisión con la que se había venido manejando hasta ese momento.

Así, evidenció de forma autónoma lo que llamó el subprincipio de idoneidad, el subprincipio de necesidad y, también, un tercer subprincipio, el de proporcionalidad, como ingredientes del principio de proporcionalidad en sentido amplio.

A pesar de la falta de precisión técnica en la denominación del tercer subprincipio, la Corte de Transición, en el caso que se comenta, pasó a dotar de una definición y contenido básico a cada uno de los subjuicios que integran el principio de proporcionalidad en sentido amplio con el fin de desarrollar el test propuesto ${ }^{78}$.

No obstante, si bien la Corte definió correctamente el alcance de cada uno de los subprincipios o subjuicios del test, su aplicación no fue la más precisa. Confirmada la idoneidad en el caso concreto, en el juicio de necesidad, el órgano jurisdiccional, a pesar de que alcanzó a definirlo de forma adecuada, terminó por justificar que la vigencia de la norma encontraba un respaldo en el marco de la propia Constitución, desatendiendo el juicio valorativo que impone el análisis de la necesidad de la medida empleada.

Es decir, desconociendo que el subjuicio de necesidad no tiene por objeto la relación causal que existe entre la medida cuestionada y su pretendida finalidad, sino la comparación entre dos medidas alternativas en relación con un mismo $\mathrm{fin}^{79}$, la Corte diluyó la fundamentación correcta de la aplicación del principio.

cuerpo normativo diferentes registros. Por otro lado, en cuanto a la inconstitucionalidad de fondo, se alegaron como derechos fundamentales violados: la seguridad jurídica, el derecho a la intimidad, la prohibición constitucional de confiscación, entre otros.

76 Véase, la sentencia de la Corte 002-11-SIN-CC, p. 9, de fecha 21/06/2011.

77 Vale mencionar que en este fallo, el apartado de la Corte que llama test de razonabilidad, más allá de una argumentación retórica, no cumplió con desarrollar, con una exigencia metodológica, un test propiamente dicho.

${ }^{78}$ En lo que respecta a la definición del subprincipio de necesidad, la Corte no es clara. Sin embargo, su argumentación se enmarca dentro de lo que la teoría del derecho exige para definir el subjuicio de necesidad.

79 GonzÁlez Beilfus, El principio de proporcionalidad en la jurisprudencia del Tribunal Constitucional..., 104. 
Por otro lado, tampoco se hizo ninguna mención al grado de afectación de la medida a los derechos en relación al fin propuesto. Dicho en otras palabras, no se verificó el grado de intensidad de la intervención de la medida cuestionada sobre los derechos fundamentales, siendo que, una intervención legislativa leve sobre los derechos habilita un control menos intenso, en tanto que, una intervención intensa sobre los mismos debe ser objeto de un control material más riguroso ${ }^{80}$.

Como sucedió con los casos 004-12-SIN-CC, 005-12-SIN-CC o 010-12-SIN-CC, donde la referencia de la Corte al principio de proporcionalidad sólo fue enunciativa, sin haber desarrollado ningún test de proporcionalidad en debida forma, también la sentencia 019-12-SIN-CC, a pesar de que contaba con el antecedente de la sentencia 002-11-SIN-CC, -en donde, de alguna manera, se había definido la estructura básica del principio a partir de los subjuicios que lo integran- dejó pasar la ocasión de dar un contenido riguroso a algún test que reflejara una utilización controlable del principio.

En este caso, el órgano de revisión constitucional, más allá de indicar que resultaba preciso analizar la norma cuestionada a la luz del principio de proporcionalidad en el marco de la idoneidad, necesidad y proporcionalidad en sentido estricto ${ }^{81}$, añadiendo una argumentación general en torno a la idoneidad del fin, no terminó por concretar cada uno de los subjuicios de una manera adecuada.

Como se evidencia, la temprana utilización del principio de proporcionalidad en la jurisprudencia de la Corte, con sus pequeños avances y múltiples inconsistencias, no se vio acompañada por una concepción clara y uniforme de su aplicación a los casos concretos. En efecto, no se establecieron perfiles definidos en la jurisprudencia constitucional acerca de la utilización del principio.

Probablemente, las causas que permiten explicar por qué la Corte apenas se esforzó en definir y concretar el contenido normativo del principio de proporcionalidad son varias. Por un lado, la propia indeterminación del concepto de proporcionalidad, que parece remitir a una genérica relación

${ }^{80}$ BeRnal Pulido, El principio de proporcionalidad y los derechos fundamentales..., 789. Un caso en que la Corte Constitucional ecuatoriana para el período de Transición ha procedido de alguna manera a realizar un juicio de intensidades es el resuelto por la sentencia 002-09-SAN-CC, de fecha 02/04/2009. Se trata de una acción por incumplimiento contra un pronunciamiento del Procurador General del Estado, Gerente General y Subgerente Regional de la Corporación Aduanera ecuatoriana.

${ }_{81}$ Véase, la sentencia de la Corte 019-12-SIN-CC, p. 20, de fecha 26/04/2012. Cabe destacar que en este caso, a diferencia de lo que sucedió con la sentencia 002-11-SIN-CC, de fecha 21/06/2011 donde el tercer subjuicio del test de proporcionalidad fue calificado, solamente, como subprincipio de proporcionalidad, aquel fue denominado como proporcionalidad en sentido estricto. Es decir, de una forma más técnica. 
entre dos elementos -medio y fin- ligado a un valor de justicia; por otro lado, el surgimiento de una Corte nueva encargada de dar vigencia efectiva al nuevo texto constitucional de 2008; finalmente, la dificultad de concretar los contornos difusos de un concepto de carácter abierto, que tiene relación con otros principios interpretativos, contribuyeron a su indefinición ${ }^{82}$.

Ejercicios de jurisprudencia dispersos, poco precisos y más bien intuitivos en relación al principio de proporcionalidad, constituyen una constante en el período inicial de la Corte de Transición, a pesar de que algunos estudios hayan reflejado de manera general -sin un referencia a un principio en concreto, sino más bien, a algunas competencias generales de la Corte-, que el parámetro de claridad conceptual utilizado por el órgano de revisión ha observado una tendencia a la mejora ${ }^{83}$.

\subsection{Primera Corte Constitucional}

Si el período de estudio referido a la Corte de Transición arrojó como conclusión la utilización de un uso intuitivo y confuso del principio de proporcionalidad, en este nuevo período, aun cuando se puede constatar una utilización más depurada del principio, no puede decirse que el mismo haya logrado consolidarse en el ejercicio de la práctica jurisdiccional de la Primera Corte Constitucional.

A pesar de que la utilización del término «proporcional» o «proporcionalidad» aparece cada vez con mayor frecuencia en el ejercicio de las tareas de revisión de la Corte, su aplicación en la mayoría de los casos sigue siendo general, dispersa y poco uniforme, aunque en casos puntuales se pueda evidenciar un criterio más refinado en su uso.

Por ejemplo, en la sentencia 010-13-SIN-CC, donde se analizó la constitucionalidad de algunas disposiciones de la Ley Orgánica del Consejo de Participación Ciudadana y Control Social, así como del Reglamento para el concurso de oposición y méritos para la integración del Consejo de Participación Ciudadana y Control Social, la Corte, luego de admitir que el legislador puede restringir el ejercicio de los derechos fundamentales, concretamente el derecho de participación y acceso a la función pública, indicó-, que dicha limitación, restricción como lo llama la Corte, tiene que

${ }^{82}$ GonzÁlez BeILfuss, El principio de proporcionalidad en la jurisprudencia del Tribunal Constitucional..., 24.

${ }^{83} \mathrm{Al}$ respecto puede verse el Estudio sobre la argumentación de las sentencias de la Corte Constitucional ecuatoriana (Enero 2010 a Diciembre de 2012), Centro de Derechos Humanos-Facultad de Jurisprudencia Pontificia Universidad Católica del Ecuador PUCE, Serie Investigación Nro. 3, (2015): 44. 
ser razonable y proporcional, respetando siempre el contenido esencial de los derechos ${ }^{84}$.

No obstante, a pesar de que la Corte habría manifestado que una intervención en el ejercicio de los derechos debe estar ajustada a los cánones de la razonabilidad y la de proporcionalidad, en ningún momento desarrolló una estructura o contenido de dichos principios. Sin llegar a diferenciar o desarrollar tales conceptos, su argumentación fue más bien general y repetitiva ${ }^{85}$.

De la misma manera, en la sentencia 012-13-SIN-CC, a pesar de que la Corte se refirió, en el marco del principio de igualdad, que toda diferencia basada en una dimensión subjetiva es sospechosa y, por ende, debe ser sometida a un «riguroso análisis de razonabilidad y proporcionalidad», dicha alusión a la razonabilidad y proporcionalidad no pasó de una simple enunciación.

A pesar de que en este caso se utilizó el principio de igualdad para juzgar la constitucionalidad de la norma impugnada, vinculándolo a la idea de razonabilidad y proporcionalidad, tal como había sucedido en la Corte de Transición, el órgano jurisdiccional en ningún momento estructuró el anunciado «riguroso» test de razonabilidad y proporcionalidad.

$\mathrm{Y}$ es que la simple enunciación del principio de proporcionalidad no es una casualidad en la argumentación de la Corte. También en las sentencias 006-14-SIN-CC y 005-15-SIN-CC faltó una utilización estricta del principio proporcionalidad con todos los subjuicios que lo integran, a pesar de que la Corte se ha referido a él en el fundamento de sus resoluciones, como el argumento trascendental de su decisión.

En la sentencia 006-14-SIN-CC, independientemente de la decisión adoptada que declaró la inconstitucionalidad parcial de la Ley de ejercicio profesional de óptica y optometría y su Reglamento, y más allá de una referencia a que el medio normativo empleado por el legislador no resultaba razonable en relación con el fin propuesto ${ }^{86}$, la alusión al principio de proporcionalidad como una herramienta idónea de evaluación de las decisiones que

${ }^{84}$ Véase, la sentencia de la Corte 010-13-SIN-CC, pp. 44-47-49, de fecha 25/09/2013.

${ }^{85}$ En varios pasajes de la sentencia 010-13-SIN-CC, de fecha 25/09/2013, el argumento central de la Corte en torno a las facultades del legislador, así como sobre la posibilidad de limitación de los derechos fundamentales sobre la base de los principios de razonabilidad y proporcionalidad, fue repetitiva.

${ }^{86}$ En la sentencia en cuestión, que juzgaba la constitucionalidad de la Ley de ejercicio profesional de óptica y optometría y su Reglamento, que prohibía a los médicos oftalmólogos participar en actividades económicas tales como ser dueños, socios o accionistas de almacenes de óptica, pretendiendo satisfacer el derecho a la salud pública, se declaró que dicha previsión resultaba irrazonable. Véase la sentencia de la Corte 006-14-SIN-CC, p. 17 , de fecha 24/09/2014. 
intervienen sobre derechos fundamentales, nuevamente fue enunciativa y general.

En la sentencia 005-15-SIN-CC, algunas referencias generales sobre la razonabilidad y la proporcionalidad ligadas al principio de igualdad, así como la recurrente deferencia al legislador democrático y su margen de configuración legislativa, le sirvieron a la Corte para negar la demanda de inconstitucionalidad propuesta ${ }^{87}$.

Por otro lado, como ha sido común tanto en la Corte de Transición, como en la Primera Corte, en los casos 001-14-SIN-CC, 012-13-SIN-CC, 006-15-SIN-CC y 011-15-SIN-CC se vinculó el principio de proporcionalidad al juicio de igualdad. Lo cierto es que, a pesar de existir una relación entre los principios para poder juzgar tratamientos tachados de discriminatorios, en la jurisprudencia constitucional no ha quedado del todo claro el sentido y alcance de cada uno de los principios cuando los mismos son puestos en relación, lo cual ha contribuido a la dispersión y la imprecisión de la Corte en el momento de fundamentar sus fallos.

En otros casos se abordó el tema objeto de discusión a través del principio de igualdad, pero sin decir nada sobre el principio de proporcionalidad ${ }^{88}$. Es decir, en unos casos se hizo una referencia expresa a la proporcionalidad en el marco de la igualdad y en otros no, situación que demuestra la falta de precisión de la Corte en el uso de estos conceptos, así como una fuerte dosis de discrecionalidad en su aplicación.

Aun así, de forma similar a lo que sucedió con la Corte de Transición en la sentencia 002-11-SIN-CC, la primera Corte Constitucional, en la sentencia 003-14-SIN-CC, sobre la Ley de Comunicación, aplicó un test de proporcionalidad con algún grado de concreción, pretendiendo afirmar la utilidad del principio en materia de control abstracto de norma, frente a la imprecisión con la que se había venido manejando.

Para tal propósito, la sentencia 003-14-SIN-CC tomó como referencia la 048-13-SCN-CC, acerca de una consulta de norma jurídica (Ley Reformatoria al Título V, libro II del Código Orgánico de la Niñez y Adolescencia y la Tabla de pensiones alimenticias mínima), en la cual la Corte enfatizó el

${ }^{87}$ En esta sentencia, la Corte argumentó que la suficiencia de motivos que justifican el trato diferente aplicado al reingreso laboral de los ex servidores de la Asamblea Nacional, así como al ingreso de aspirantes a trabajar en ella, frente al reingreso laboral de los ex servidores o al ingreso de aspirantes a trabajar en las otras instituciones públicas, responde a un test de razonabilidad. No obstante, nunca desarrolló dicho test y poco sirvió dicha afirmación para clarificar el concepto del principio de proporcionalidad que manejó la Corte. Véase, la sentencia de la Corte 005-15-SIN-CC, p. 16, de fecha 18/03/2015.

${ }_{88}$ Véase, las sentencias de la Corte 005-14-SIN-CC, de fecha 24/09/2014 y 009-15-SIN-CC, de fecha 31/03/2015. 
carácter relacional del principio de proporcionalidad ${ }^{89}$ así como la posibilidad de colisión que en el ejercicio de control abstracto puede suscitarse, al confrontar los principios que subyacen a la norma cuestionada en relación con otros derechos fundamentales en juego ${ }^{90}$.

La Corte, en varios pasajes de la sentencia 003-14-SIN-CC, estructuró un test de proporcionalidad con el fin de juzgar la constitucionalidad de las normas impugnadas, haciendo una especial mención a los diferentes subjuicios o subprincipios que integran la proporcionalidad ${ }^{91}$, incluso, con una referencia a la intensidad de la intervención en relación con el grado de satisfacción del derecho ${ }^{92}$.

No obstante, a pesar de haber estructurado adecuadamente las bases del test de proporcionalidad para juzgar la constitucionalidad de algunas de las normas impugnadas, en otros pasajes de la misma sentencia, la Corte se limitó a decir que otras normas, lejos de contemplar un límite inconstitucional al derecho a la información, eran proporcionales, sin haber estructurado o desarrollado ningún test que diera soporte a tal conclusión $n^{93}$, llevando el ejercicio argumental de la Corte a un juego amplio de discrecionalidad judicial.

En la sentencia 007-14-SIN-CC, cuyo objeto de control se relacionó con la impugnación de la norma de la Ley Orgánica del Consejo de Participación Ciudadana y Control Social que exigía la renuncia previa de los funcionarios públicos antes de la convocatoria a concursos públicos o conformación de ternas, el test de proporcionalidad trazado por la Corte para juzgar el grado de intervención del legislador sobre el contenido de los derechos también

${ }^{89}$ Sobre lo dicho, la Corte afirmó: «...Tomando en cuenta los criterios señalados, con el objeto de realizar el test que propone el principio de proporcionalidad, esta Corte deberá someter a la medida analizada al examen sobre su idoneidad, necesidad y proporcionalidad en sentido estricto...». Véase, la sentencia de la Corte 048-13-SCN-CC, p. 71, de fecha 04/09/2013.

${ }^{90}$ En esta sentencia la Corte indicó: «...debe verificarse si la Tabla está encaminada a proteger un fin constitucionalmente válido y si este se halla en eventual colisión con otro». Véase, la sentencia 048-13-SCN-CC, p. 71, de fecha 04/09/2013.

91 Véase, en la sentencia de la Corte 003-14-SIN-CC, de fecha 17/09/2014, el análisis de los arts. 18 (pp. 100 y ss. del fallo), 26 (pp. 134 y ss. del fallo), 42 (pp. 164 y ss. del fallo) de la Ley de Comunicación.

${ }^{92}$ La sentencia mencionó que: «Por otra parte, el no limitar levemente el derecho de los medios de comunicación y no establecer una medida que implica una sanción en el cambio administrativo para el caso de aquellos que, deliberada y reiteradamente, no difundan información de interés general, pondrá en grave riesgo el derecho de todas las persona a recibir información de los acontecimientos de interés general, por lo que una restricción leve de los derechos de los medios de comunicación para evitar un riesgo grave de vulneración de los derechos de todas las personas, indudablemente supera el examen de proporcionalidad...». Véase, la sentencia de la Corte 003-14-SIN-CC, p. 102, de fecha 17/09/2014.

${ }_{93}$ Véase, la sentencia de la Corte 003-14-SIN-CC, pp. 124-125, de fecha 17/09/2014. 
incluyó una mención a los subjuicios de idoneidad, necesidad y proporcionalidad en estricto sentido. A pesar de aquello, el desarrollo de cada uno de ellos no fue el más adecuado.

Podría pensarse, quizá, que este momento de invocación y aplicación del principio de proporcionalidad en la jurisprudencia de la Corte, podría haber sido el inicio de una paulatina institucionalización en el uso del mismo, una vez precisado su contenido normativo y su estructura básica. Sin embargo, se trataría de una conclusión precipitada, puesto que, posteriormente, la propia Corte ha sido inestable en su jurisprudencia, sin haber logrado consolidar una estructura analítica ambiciosa del principio interpretativo.

¿Por qué la Corte decide en unos casos aplicar el principio de proporcionalidad con su estructura básica y en otros le basta la simple enunciación? ¿No se diluye la tarea del control racional de la Corte en un ejercicio de prácticas retóricas no controlables que ahondan la denominada crítica contramayoritaria? ¿Cuál es la justificación racional que utiliza la Corte para concluir en unos casos que las normas cuestionadas son simplemente proporcionales y en otros no?

Como se ha visto, no existe en la jurisprudencia de la Corte unos perfiles definidos del principio de proporcionalidad, que sirvan de pauta argumentativa controlable en materia interpretativa, puesto que el discurrir argumental de aquélla se ha movido, más bien, en términos genéricos, muchas veces poco convincentes, altamente discrecionales y escasamente motivados.

Por otro lado, no existe en la jurisprudencia de la Corte, decisiones que, bajo el test de proporcionalidad, y una vez superado el análisis de la idoneidad y necesidad, las normas impugnadas hayan sido declaradas desproporcionales en sentido estricto.

En otras palabras, como ha sido rescatado en algunos estudios comparados sobre la materia, una medida idónea que es a la vez indispensable desde la visión de la Corte, casi siempre resultará, al propio tiempo, ponderada en relación con los derechos que juegan en sentido contrario ${ }^{94}$.

De suerte que, superada la idoneidad, la Corte no encontraría parámetro alguno apto para desviar la atención del fallo hacia la convalidación de la medida en cuestión. Lo cual explica también que, en materia de control abstracto de norma, la revisión judicial por vía del test de proporcionalidad no ha gravitado esencialmente sobre un juicio de ponderación o de proporcionalidad en sentido estricto, sino, sobre la idoneidad y necesidad del medio utilizado ${ }^{95}$.

${ }^{94}$ Pedro Grández CASTRO, «El principio de proporcionalidad en la jurisprudencia del TC peruano» en El principio de proporcionalidad en el derecho comparado, (Lima: Palestra, 2010), 361.

${ }_{95}$ Probablemente por ello sigue pendiente un desarrollo exigente de argumentación por parte de la Corte en relación al juicio de ponderación constitucional como un método 
Asimismo, parece bastante improbable que, en la práctica, una medida adoptada por el legislador resulte absolutamente inidónea para conseguir un fin propuesto en el marco de una Constitución amplia en derechos protegidos.

Por lo general, el abanico de posibilidades que brinda una Constitución amplia en derechos, habilita, como consecuencia, la construcción de un argumento que permita superar con cierta facilidad el juicio de idoneidad al cual está sometida una norma impugnada.

Es más, si se piensa que tampoco se exige siempre que la finalidad perseguida tenga rango expresamente constitucional para ser considerada idónea, sino que basta que sea constitucionalmente legítima, esto es, que quepa dentro de las posibilidades de actuación que la Constitución permite al legislador, el margen puede resultar aún más amplio y flexible.

Esto podría tener algunas lecturas, tal como sostiene Pedro Grández. La menos optimista sería aquella que considera que la proporcionalidad en sentido estricto no aporta mayores controles al test de proporcionalidad en sentido amplio, por implicar un juicio muy subjetivo. Otra lectura posible evidenciaría que la Corte no es lo suficientemente estricta en el tercer subjuicio del test y, consecuentemente, éste se habría convertido en un mero paso formal dentro de una construcción que exigiría mayores capacidades argumentativas ${ }^{96}$.

En lo que respecta al criterio de necesidad como parte del principio de proporcionalidad en sentido amplio, éste resulta ser un tanto más complejo que el subjuicio de idoneidad. Ello resulta lógico si se tiene presente que la relación causal que presenta el subjuicio de necesidad no tiene por objeto la relación que debe presentarse entre la medida cuestionada y su pretendida finalidad, sino la comparación entre dos medidas alternativas que compiten como idóneas para alcanzarla ${ }^{97}$, lo que no significa, sin embargo, que éste no sea un juicio normativo, como lo ha sugerido K. Larenz ${ }^{98}$.

Por otro lado, tampoco existe en la jurisprudencia ecuatoriana una carga argumentativa que sustente una motivación suficiente en relación con un test de intensidades sobre los grados de satisfacción o afectación a los derechos en pugna.

de fundamentación racional de las decisiones judiciales. Aun así, existen otras facultades de la Corte en donde puede haberse evidenciado en mayor medida un desarrollo de dicho juicio, como por ejemplo, la competencia de revisión o la que recae sobre el conocimiento de las acciones extraordinarias de protección.

96 Grández CAStro, El principio de proporcionalidad en la jurisprudencia del TC peruano..., 361 .

97 Ibíd., 104.

98 LAREnZ, Metodología de la Ciencia del derecho..., 472. 
Contrariamente, bajo el argumento simple que ha esgrimido la Corte en alguno de sus fallos, en el sentido de que se trata de intervenciones leves en los derechos ${ }^{99}$, podría pensarse que una injerencia debería ser absoluta para ser considerada grave.

Finalmente, en lo relativo al subjuicio o subprincipio de proporcionalidad en sentido estricto, también se mantiene pendiente un desarrollo exigente de argumentación en la Corte, que logre vencer la crítica de falta de racionalidad en su utilización ${ }^{100}$.

De todas formas, el principio de proporcionalidad ha ido extendiéndose progresivamente, como es natural, en relación con varios derechos fundamentales y distintas materias, como por ejemplo, en material electoral ${ }^{101} \mathrm{y}$, muy ampliamente, en materia tributaria, como resultado de la reiterada jurisprudencia expedida en casos similares por parte de la Corte ecuatoriana ${ }^{102}$. Aun así, la consecuencia ha sido la misma: una retórica general y dispersa que se ha constituido en el principal obstáculo para la formalización de principio.

Si bien en las condiciones expuestas se puede considerar que el papel otorgado al principio de proporcionalidad es altamente discrecional y subjetivo, lo que impondría la urgente necesidad de repensar su utilización, parece altamente difícil dar marcha atrás en su aplicación.

Lo que queda es la exigencia de un uso más depurado y técnico de la aplicación del principio, que lo convierta en un canon de legitimidad aceptable en el marco de las decisiones que adopta la Corte.

99 Véase, la sentencia de la Corte 003-14-SIN-CC, de fecha 17/09/2014.

100 GonZÁlez BeIlfus, El principio de proporcionalidad en la jurisprudencia del Tribunal Constitucional..., 370

101 Véase, la sentencia de la Corte 019-15-SIN-CC, de fecha 31/03/2015. También la sentencia $028-12-S I N-C C$, de fecha 17/10/2012, se refirió al principio de proporcionalidad en materia electoral.

102 Véase, las sentencias de la Corte 016-15-SIN-CC, de fecha 13/05/2015; 021-15-SIN-CC, de fecha 01/07/2015; 022-15-SIN-CC, de fecha 01/07/2015; 025-15-SINCC, de fecha 22/07/2015; 026-15-SIN-CC, de fecha 22/07/2015; 028-15-SIN-CC, de fecha 29/07/2015; 029-15-SIN-CC, de fecha 29/07/2015; 030-15-SIN-CC, de fecha 29/07/2015; 031-15-SIN-CC, de fecha 05/08/2015; 032-15-SIN-CC, de fecha 05/08/2015; 033-15-SIN-CC, de fecha 12/08/2015; 035-15-SIN-CC, de fecha 02/09/2015; 037-15-SINCC, de fecha 16/09/2015; 038-15-SIN-CC, de fecha 16/09/2015; 041-15-SIN-CC, de fecha 16/09/2015; 042-15-SIN-CC, de fecha 16/09/2015; 043-15-SIN-CC, de fecha 23/09/2015; 044-15-SIN-CC, de fecha 23/09/2015; 045-15-SIN-CC, de fecha 23/09/2015; 046-15-SIN-CC, de fecha 23/09/2015;049-15-SIN-CC, de fecha 23/09/2015; 051-15-SINCC, de fecha 21/10/2015; 052-15-SIN-CC, de fecha 21/10/2015; 053-15-SIN-CC, de fecha $21 / 10 / 2015$; 054-15-SIN-CC, de fecha 21/10/2015;055-15-SIN-CC, de fecha $21 / 10 / 2015$, entre otras. 
En palabras de Markus González, «el carácter principial de buena parte de los preceptos constitucionales y, singularmente, de las normas que garantizan derechos fundamentales y la posibilidad de los poderes públicos de restringirlos, así como la necesidad constante de resolver colisiones entre bienes jurídicos, están en el origen, en efecto, de la consolidación del principio de proporcionalidad» ${ }^{103}$.

\section{REFLEXIONES FINALES}

El principio de proporcionalidad no se trata de un concepto jurídico inventado por la jurisprudencia y la doctrina constitucional de la segunda mitad del siglo Xx. Tras la consolidación del Estado democrático, la utilización del principio de proporcionalidad se ha generalizado viniendo a desempeñar un papel relevante, fundamentalmente, en el área del Derecho constitucional y de los Derechos humanos. De ahí que, la generalizada aceptación que hoy en día goza en la doctrina jurídica el principio de proporcionalidad, conlleva que todos los poderes públicos estén sometidos al mismo en su doble vertiente: como criterio de actuación y parámetro de control.

Sin embargo, a pesar del auge en su utilización, una de las deficiencias más notorias que puede evidenciarse es aquella que se refiere a su inconsistencia terminológica. Quizá el problema se encuentre en la pluralidad de significados o el uso disímil que puede adscribirse al término ponderación y su asimilación directa a la idea de proporcionalidad.

Por otro lado, ha quedado claro que el principio de proporcionalidad en sentido amplio es un concepto esencialmente relacional que se encuentra ligado siempre a un sustrato normativo, vinculado a una determinada teoría de la interpretación que permite medir la licitud de toda intervención de género normativo en el ejercicio de los derechos desde un concreto perfil, que es evitar la inutilidad, necesidad, desequilibrio o desproporción de una medida empleada.

Ahora bien, en el caso ecuatoriano, la concreción del criterio de proporcionalidad invocado por la Corte como principio interpretativo ha sido más bien confusa y tan solo enunciativa en varias sentencias. Salvo casos excepcionales, que no permiten apreciar una actuación constante y uniforme ni de la Corte de Transición, ni de la Primera Corte Constitucional, la amplia discrecionalidad en la valoración del principio de proporcionalidad por parte de la Corte ecuatoriana resulta patente. Esto es especialmente criticable en la Primera Corte Constitucional, que a pesar de la experiencia acumulada, tan solo ha avanzado en un uso algo más depurado del principio sin ser consistente.

${ }^{103}$ GonzÁlez Beilfuss, El principio de proporcionalidad en la jurisprudencia del Tribunal Constitucional..., 125. 
Una revisión atenta de la jurisprudencia de la Corte no hace más que poner en evidencia que la utilización del principio de proporcionalidad como canon de constitucionalidad, no es del todo alentadora.

Cabe destacar que a pesar de que la utilización del principio de proporcionalidad dentro del control de constitucionalidad pueda resultar altamente discrecional y merezca fundados reparos, parece altamente difícil dar marcha atrás en su utilización por parte de la Corte Constitucional ecuatoriana. Es más, como era de esperarse, el uso del principio de proporcionalidad ha ido extendiéndose progresivamente en los diferentes fallos de la Corte.

Lo que queda es la exigencia de un uso mucho más depurado y técnico del principio capaz de convertirlo en un canon de legitimidad que dote de racionalidad y previsibilidad a las decisiones que adopta la Corte. De lo contrario, habríamos asistido como lo indicara Lambert en su momento, a un verdadero gobierno de los jueces caracterizado, además, por su déficit de legitimación democrática directa, e irresponsable respecto de sus actuaciones.

TITLE: The principle of proportionality as a canon of constitutionality: an approach to the Ecuadorian case

RESUMEN: Debido a que un grado de legitimidad del ejercicio de las funciones jurisdiccionales ${ }^{104}$ puede ser apreciado a través de la utilización y puesta en práctica de ciertos parámetros o cánones objetivos del control de constitucionalidad, como por ejemplo, el principio de proporcionalidad; un análisis de dicho instrumento jurídico puede resultar relevante a efectos de justificar un grado de intervención racional y controlable del órgano jurisdiccional sobre la obra del legislador.

Es verdad que existen otros principios, técnicas argumentales, métodos de interpretación o herramientas jurídicas que son utilizadas por la Cortes Constitucionales o Tribunales Constitucionales contemporáneas en el ejercicio de su actividad de control, sin embargo, fijar una precisión conceptual del principio, analizar su estructura y composición como método, así como, evidenciar al principio de proporcionalidad como parámetro o canon objetivo de constitucionalidad y fuente de legitimidad de la revisión judicial en la Corte ecuatoriana, es el objetivo del presente artículo.

${ }^{104}$ Función jurisdiccional será entendida como aquella facultad atribuida a las juezas y jueces para juzgar y hacer ejecutar lo juzgado. Para el caso en análisis, la Corte Constitucional ecuatoriana ejerce funciones jurisdiccionales en materia constitucional como máximo órgano de control, interpretación constitucional y administración de justicia en esta materia constitucional. Véase, art. 429 de la Constitución de la República del Ecuador de 2008. 
PALABRAS CLAVE: proporcionalidad, principio de proporcionalidad, canon de constitucionalidad, legitimidad, racionalidad y proporcionalidad.

ABSTRACT: Because a range of the legitimacy of the exercise of jurisdictional functions can be assessed through the use and the implementation of certain parameters or objective canons of the constitutionality control, such as the principle of proportionality, an analysis of that instrument may be relevant in order to justify a degree of national intervention and controllable by the court over the work of the legislator.

It is a fact that there are other principles, techniques of argumentation, methods of interpretation or legal tools that are used by the Constitutional Courts or Contemporary Constitutional Courts in the exercise of their control activity; however, establishing a conceptual precision of the principle, analyzing its structure and composition as a method, as well as, evidencing the principle of proportionality as a parameter or objective canon of constitutionality and source of legitimacy of judicial review in the Ecuadorian Court, is the objective of this article.

KEY WORDS: proportionality, principle of proportionality, canon of constitutionality, legitimacy, rationality and proportionality. 